\title{
Partial Parameter Analysis of the Stability of Small and Medium Span Steel-concrete Composite Bridges
}

\author{
Haoqi Li ${ }^{1}$ \\ ${ }^{1}$ School of Highway, Chang'an University \\ Nan' erhuan Road, Xi'an, China \\ lhq@chd.edu.cn
}

\begin{abstract}
Based on a $3 \times 35 \mathrm{~m}$ steel-concrete composite beam bridge of a certain highway project, the finite element software is used to establish a non-linear solid model, and the stability safety factor is used as an evaluation index to perform parameter analysis on the stability and safety of small-span steel-concrete composite continuous beams. The corresponding influence law will be obtained. Except for the width-to-thickness ratio of the compressed flange, the stability and safety of $3 \times 35 \mathrm{~m}$ straight beams are better than those of curved beams in each parameter analysis, and the stability and safety of curved beams is more affected by various structural parameters. For 3 $\times 35 \mathrm{~m}$ straight beams, from the perspective of stability, it is recommended to consider the $8.75 \mathrm{~m}$ beam spacing to save steel. From the comprehensive consideration of structural stability and safety and the amount of steel used, it is recommended that the high-span ratio of medium-small-span steel-concrete composite beams be 1/20. Local buckling will occur in the relatively thin positions of the compressed flange and the web. The value of the width-to-thickness ratio of the compressed flange of a straight beam is suggested.
\end{abstract}

Keywords: Precast composite beam, Stability, Parametric analysis, Small and medium spans.

\section{Introduction}

With the rapid development of social economy and highway transportation, steel-concrete composite beam bridges with small and medium spans have been increasingly studied and applied. In the design of steel structures and composite structures, stability is an important point that must be considered. In the current code, only the formula for calculating the overall stability coefficient of I-shaped simply-supported beams and the relevant provisions on the limits of the width-tothickness ratio of the wing and the height-to-thickness ratio of the web are given. Therefore, it is necessary to conduct indepth analysis and research on the stability of small and medium span steel plate composite bridges.

\section{Analysis Method and Content}

Numerical analysis method: Elastoplastic stability analysis of ABAQUS finite element program. Evaluation index: Stability was evaluated by stabilizing the structure of the safety factor. The second type of stability evaluation index is adopted, Stability safety factor $\xi$ :

$$
\xi=\frac{F_{s}+\lambda F_{c}}{F_{s}+F_{c}}
$$

Among them, $F_{s}$ is the weight of the steel beam, $F_{c}$ is the weight of the concrete bridge deck, and $\lambda$ is the loading coefficient. 


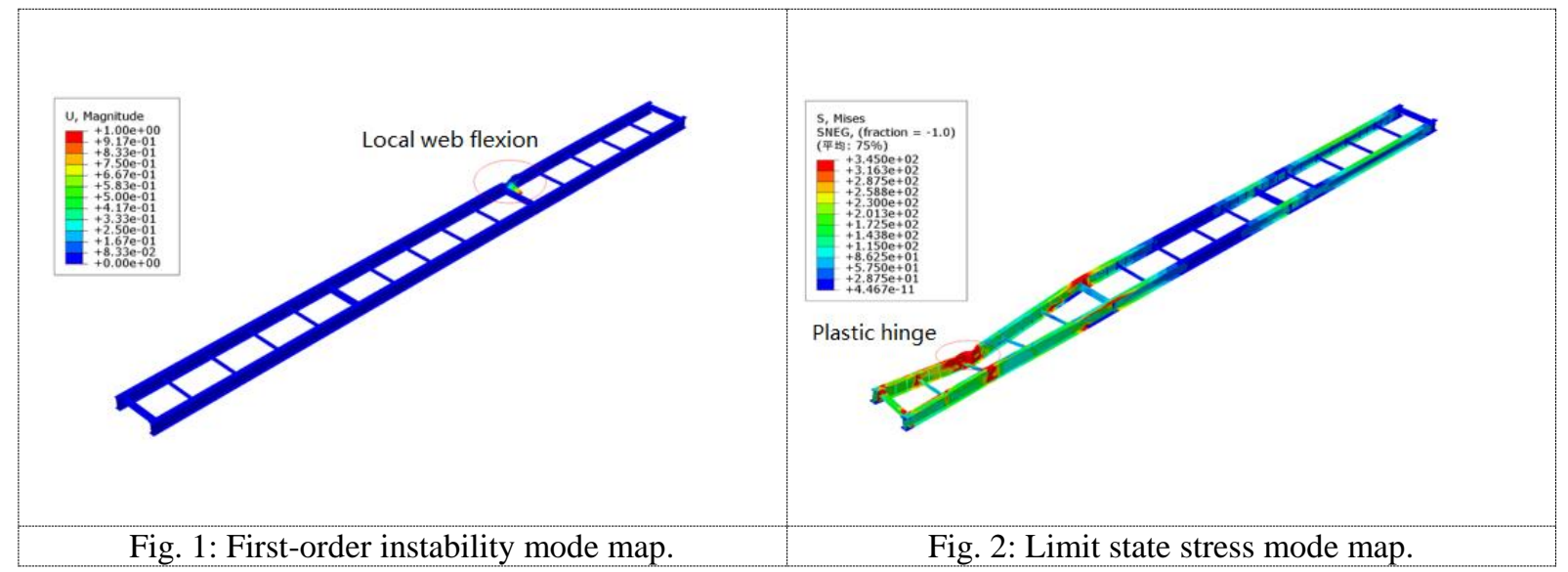

\section{Parametric Analysis}

\subsection{Beam Spacing}

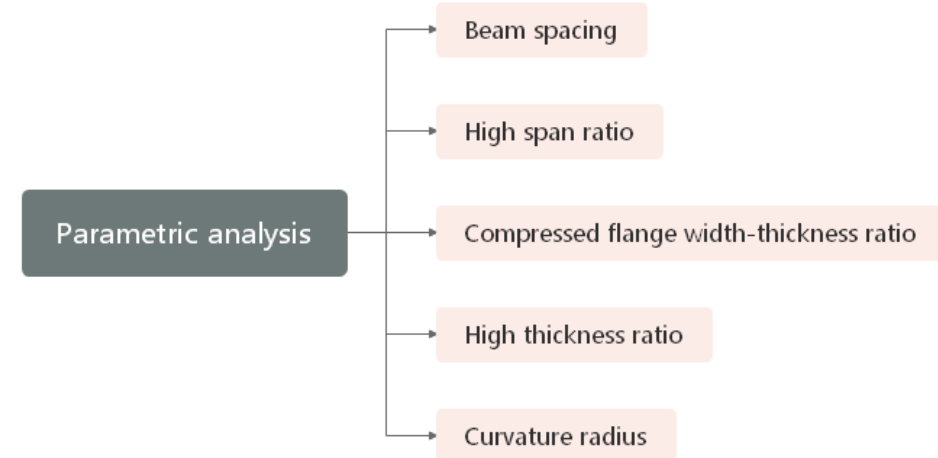

Fig. 3: Parametric analysis type diagram.

According to the principle that under the same load, the stress levels of the upper and lower flanges of the steel beam and the structural bearing capacity are the same. By changing the beam spacing in the model, we got the following data.

Table 1: Caption for table goes at the top.

\begin{tabular}{clccccc}
\hline $\begin{array}{c}\text { Beam spacing } \\
\text { / m }\end{array}$ & Load form & Loading factor $\lambda$ & $\begin{array}{c}\text { Stable ultimate } \\
\text { bearing capacity } \\
\text { KN/m }\end{array}$ & $\begin{array}{c}\text { Stable safety } \\
\text { factor }\end{array}$ & $\begin{array}{c}\text { Normal stress at mid- } \\
\text { span upper flange } \\
\text { /Mpa }\end{array}$ & Instability mode \\
\hline 35 & Uniform load & 2.9 & 107.5 & 2.47 & 345 & Lateral torsional instability \\
17.5 & Uniform load & 6.9 & 239.8 & 5.52 & 345 & Lateral torsional instability \\
11.67 & Uniform load & 8 & 275.5 & 6.34 & 345 & Lateral torsional instability \\
8.75 & Uniform load & 8.9 & 306.9 & 7.06 & 345 & Web flexion \\
7 & Uniform load & 9 & 309 & 7.11 & 345 & Web flexion \\
\hline
\end{tabular}


Table 2. Calculation results of Curved beam.

\begin{tabular}{|c|c|c|c|c|c|c|c|}
\hline Radius /m & $\begin{array}{c}\text { Beam } \\
\text { spacing / } \mathrm{m}\end{array}$ & Load form & $\begin{array}{c}\text { Loading factor } \\
\lambda\end{array}$ & $\begin{array}{l}\text { Stable ultimate bearing } \\
\text { capacityKN/m }\end{array}$ & $\begin{array}{l}\text { Stable safety } \\
\text { factor }\end{array}$ & $\begin{array}{c}\text { Normal stress at mid-span } \\
\text { upper flange /Mpa }\end{array}$ & $\begin{array}{l}\text { Instability } \\
\text { mode }\end{array}$ \\
\hline 460 & 35 & Uniform load & 2.4 & 88.7 & 2.04 & 345 & Web flexion \\
\hline 460 & 17.5 & Uniform load & 5.1 & 117.9 & 4.1 & 345 & Web flexion \\
\hline 460 & 11.67 & Uniform load & 5.9 & 205.7 & 4.74 & 345 & Web flexion \\
\hline 460 & 8.75 & Uniform load & 7.5 & 258 & 5.94 & 345 & Web flexion \\
\hline 460 & 7 & Uniform load & 8.5 & 290.2 & 6.68 & 345 & Web flexion \\
\hline
\end{tabular}

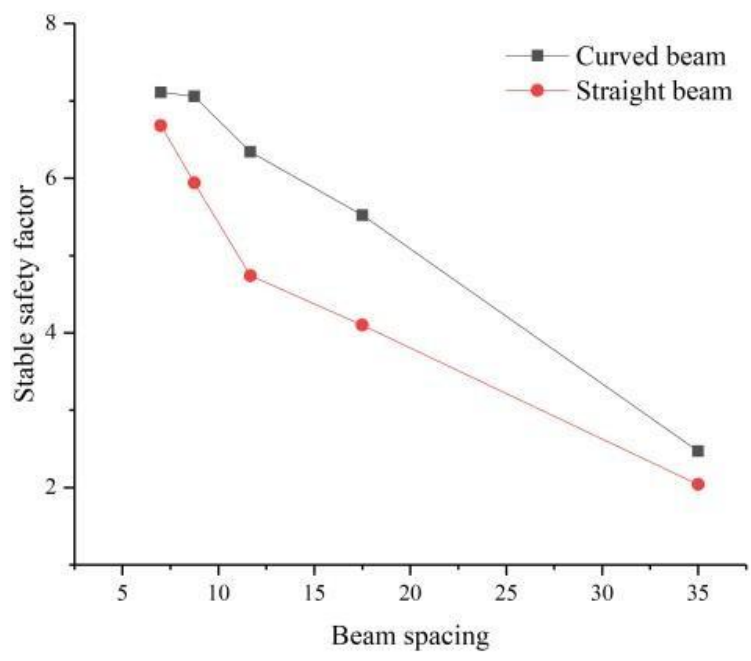

Fig. 4: Relationship between stability factor and beam spacing.

From the above chart, it can be found that as the distance between beams decreases, the stability safety factors of straight beams and curved beams gradually increase;

The stability limit bearing capacity and stability safety factor of beams with a spacing of $8.75 \mathrm{~m}$ and $7 \mathrm{~m}$ are almost the same. For $3 \times 35 \mathrm{~m}$ double I-shaped steel straight beams, from the perspective of stability, compared with the beam spacing of $\leqslant 7 \mathrm{~m}$ commonly used in current engineering, the beam spacing of $8.75 \mathrm{~m}$ can be used to meet the requirements of the specification.

\subsection{High Span Ratio}

According to the principle that under the same load, the stress levels of the upper and lower flanges of the steel beam and the structural bearing capacity are the same, the size of the upper and lower wing plates is changed as the beam height changes.

Table 3. Calculation results of straight beam.

\begin{tabular}{|c|c|c|c|c|c|c|}
\hline $\begin{array}{l}\text { High span } \\
\text { ratio }\end{array}$ & Load form & $\begin{array}{l}\text { Loading } \\
\text { factor } \lambda\end{array}$ & $\begin{array}{c}\text { Stable ultimate bearing } \\
\text { capacity } \mathrm{KN} / \mathrm{m}\end{array}$ & $\begin{array}{l}\text { Stable safety } \\
\text { factor }\end{array}$ & $\begin{array}{c}\text { Normal stress at mid-span } \\
\text { upper flange /Mpa }\end{array}$ & $\begin{array}{l}\text { Instability } \\
\text { mode }\end{array}$ \\
\hline $1 / 18$ & Uniform load & 9.1 & 310.7 & 7.15 & 345 & Web flexion \\
\hline $1 / 19.44$ & Uniform load & 9 & 309 & 7.11 & 345 & Web flexion \\
\hline $1 / 21$ & Uniform load & 8.3 & 285 & 6.59 & 345 & Web flexion \\
\hline $1 / 24$ & Uniform load & 7.8 & 269.3 & 6.19 & 345 & Web flexion \\
\hline $1 / 27$ & Uniform load & 7.5 & 259 & 5.91 & 345 & Web flexion \\
\hline
\end{tabular}


Table 4. Calculation results of curved beam.

\begin{tabular}{|c|c|c|c|c|c|c|c|}
\hline \multicolumn{2}{|c|}{ radius /mHigh span ratio } & \multirow{2}{*}{$\begin{array}{c}\text { Load form } \\
\text { Uniform load }\end{array}$} & \multirow{2}{*}{$\begin{array}{c}\begin{array}{c}\text { Loading } \\
\text { factor } \lambda\end{array} \\
9.4\end{array}$} & \multirow{2}{*}{$\begin{array}{c}\text { Stable ultimate bearing } \\
\text { capacity KN/m }\end{array}$} & \multirow{2}{*}{$\begin{array}{c}\begin{array}{c}\text { Stable safety } \\
\text { factor }\end{array} \\
7.32\end{array}$} & \multirow{2}{*}{\multicolumn{2}{|c|}{$\begin{array}{cc}\begin{array}{c}\text { Normal stress at mid- } \\
\text { span upper flange /Mpa }\end{array} & \begin{array}{c}\text { Instability } \\
\text { mode }\end{array} \\
345 & \text { Web flexion }\end{array}$}} \\
\hline 460 & $1 / 18$ & & & & & & \\
\hline 460 & $1 / 19.44$ & Uniform load & 8.5 & 290.2 & 6.68 & 345 & Web flexion \\
\hline 460 & $1 / 21$ & Uniform load & 8 & 271.5 & 6.3 & 345 & Web flexion \\
\hline 460 & $1 / 24$ & Uniform load & 7.1 & 243.5 & 5.6 & 345 & Web flexion \\
\hline 460 & $1 / 27$ & Uniform load & 5.6 & 193.5 & 4.39 & 345 & Web flexion \\
\hline
\end{tabular}

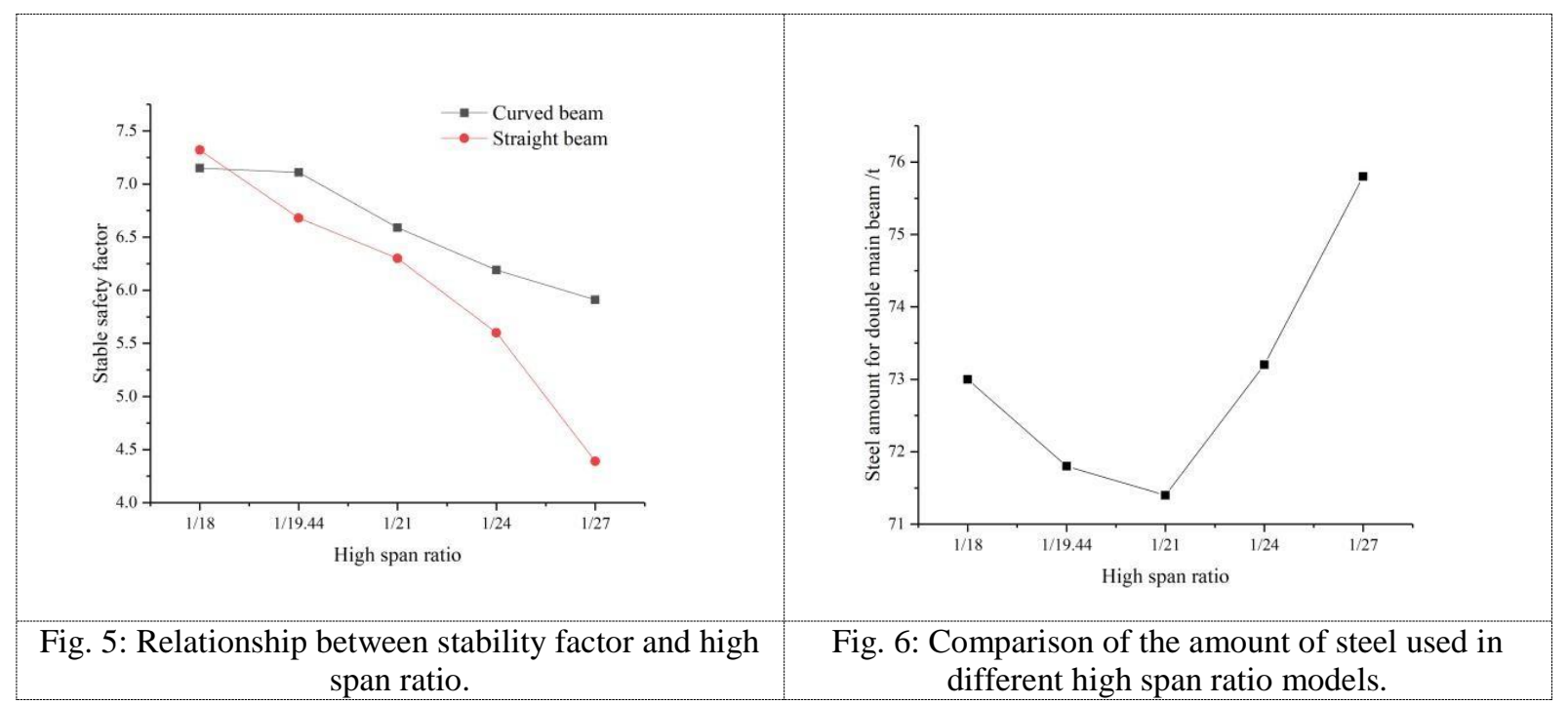

It can be seen from the Figure 5 and 6, as the high-span ratio decreases, the stability and safety factor of the structure gradually decreases, and the two are basically in a linear relationship; the stability safety factor of curved beams is more affected by the high-span ratio; Comprehensive stability and safety and economic performance factors, for small and medium-span double-steel composite continuous beam bridge, it is recommended to adopt a high-span ratio of about $1 / 20$.

\subsection{Width-Thickness Ratio}

By changing the width-thickness ratio in the model, we got the following data.

Table 5. Calculation results of straight beam.

\begin{tabular}{|c|c|c|c|c|c|c|}
\hline Width-thickness ratio & Load form & $\begin{array}{l}\text { Loading } \\
\text { factor } \lambda\end{array}$ & $\begin{array}{c}\text { Stable ultimate bearing } \\
\text { capacity } \mathrm{KN} / \mathrm{m}\end{array}$ & $\begin{array}{l}\text { Stable safety } \\
\text { factor }\end{array}$ & $\begin{array}{c}\text { Normal stress at mid-span } \\
\text { upper flange } / \mathrm{Mpa}\end{array}$ & Instability mode \\
\hline 8 & Uniform load & 9.3 & 317.6 & 7.33 & 345 & Web flexion \\
\hline 10.7 & Uniform load & 9 & 309 & 7.11 & 345 & Web flexion \\
\hline 13 & Uniform load & 8.8 & 299.5 & 6.91 & 345 & Web flexion \\
\hline 14 & Uniform load & 7.4 & 255.5 & 5.89 & 345 & Flap buckling \\
\hline 15 & Uniform load & 7.5 & 256.7 & 5.93 & 345 & Flap buckling \\
\hline 17 & Uniform load & 7.4 & 254.7 & 5.87 & 345 & Flap buckling \\
\hline
\end{tabular}


Table 6. Calculation results of curved beam.

\begin{tabular}{cccccccc}
\hline radius /m & $\begin{array}{c}\text { width- } \\
\text { thickness ratio }\end{array}$ & Load form & $\begin{array}{c}\text { Loading } \\
\text { factor } \lambda\end{array}$ & $\begin{array}{c}\text { Stable ultimate bearing } \\
\text { capacity KN/m }\end{array}$ & $\begin{array}{c}\text { Stable safety } \\
\text { factor }\end{array}$ & $\begin{array}{c}\text { Normal stress at mid- } \\
\text { span upper flange /Mpa }\end{array}$ & $\begin{array}{c}\text { Instability } \\
\text { mode }\end{array}$ \\
\hline 460 & 8 & Uniform load & 8 & 274.4 & 6.33 & 345 & Web flexion \\
460 & 10.7 & Uniform load & 8.5 & 290.2 & 6.68 & 345 & Web flexion \\
460 & 13 & Uniform load & 8.8 & 300.3 & 6.92 & 345 & Web flexion \\
460 & 14 & Uniform load & 8.7 & 296.6 & 6.85 & 345 & Web flexion \\
460 & 15 & Uniform load & 8.6 & 292.5 & 6.76 & 345 & Web flexion \\
460 & 17 & Uniform load & 8.4 & 285.3 & 6.58 & 345 & Web flexion \\
\hline
\end{tabular}

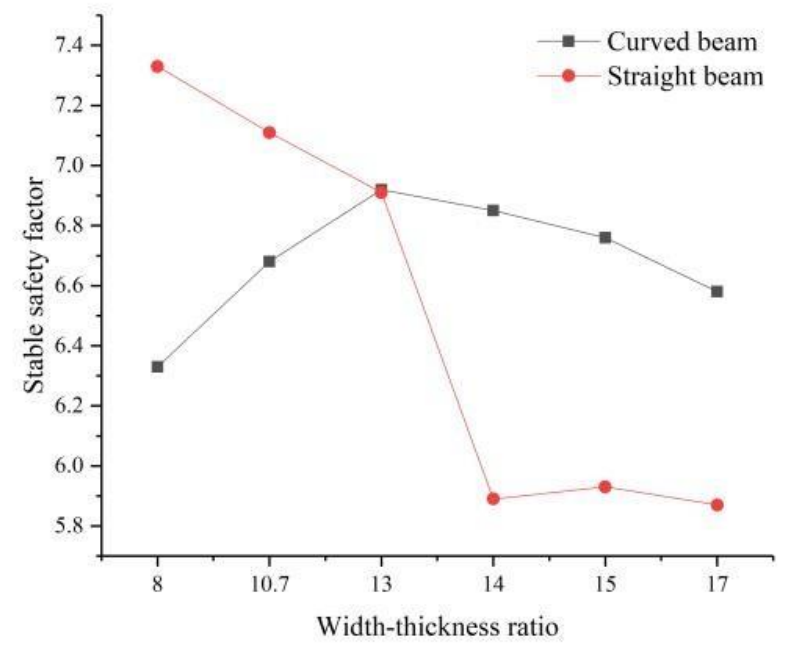

Fig. 7: Relationship between stability coefficient and aspect ratio.

From the Figure 7, it can be seen that with the increase of the width-to-thickness ratio of the compressed flange, the stability safety factor of the straight beam gradually decreases, and the stability safety factor of the curved beam is basically unchanged.

For straight beams, local buckling of steel beams will occur in relatively weak areas of both the compressed flange and the web. Studies have shown:

When the height-to-thickness ratio of the web is 50 to 80 , the width-to-thickness ratio of the compressed flange can be calculated according to Equation:

$$
\frac{b}{t}=0.02119\left(\frac{h_{0}}{t_{f}}-34.685\right)^{2}+19.177
$$

When the height-to-thickness ratio of the web is less than 50, the width-to-thickness ratio of the compressed flange is taken as 12 according to specifications;

When the height-to-thickness ratio of the web is greater than 80 , the width-to-thickness ratio of the compressed flange may be the minimum value that meets the requirements of the stress, the construction, and the arrangement of the shear pins.

\subsection{High thickness ratio}

By changing the high thickness ratio in the model, we got the following data. 
Table 7. Calculation results of straight beam.

\begin{tabular}{|c|c|c|c|c|c|c|}
\hline High thickness ratio & Load form & Loading factor $\lambda$ & $\begin{array}{c}\text { Stable ultimate bearing } \\
\text { capacity } \mathrm{KN} / \mathrm{m}\end{array}$ & $\begin{array}{l}\text { Stable safety } \\
\text { factor }\end{array}$ & $\begin{array}{c}\text { Normal stress at mid-span } \\
\text { upper flange /Mpa }\end{array}$ & $\begin{array}{l}\text { Instability } \\
\text { mode }\end{array}$ \\
\hline 64 & Uniform load & 9 & 309 & 7.11 & 345 & Web flexion \\
\hline 80 & Uniform load & 8.4 & 287.9 & 6.64 & 345 & Web flexion \\
\hline 100 & Uniform load & 7.7 & 265.6 & 6.13 & 345 & Web flexion \\
\hline 120 & Uniform load & 7.2 & 248.8 & 5.74 & 345 & Web flexion \\
\hline 140 & Uniform load & 6.7 & 230.6 & 5.32 & 345 & Web flexion \\
\hline 160 & Uniform load & 5.9 & 206.2 & 4.76 & 345 & Web flexion \\
\hline
\end{tabular}

Table 8. Calculation results of curved beam.

\begin{tabular}{cccccccc}
\hline $\begin{array}{c}\text { radius } \\
/ \mathrm{m}\end{array}$ & $\begin{array}{c}\text { High } \\
\text { thickness } \\
\text { ratio }\end{array}$ & Load form & $\begin{array}{c}\text { Loading } \\
\text { factor } \lambda\end{array}$ & $\begin{array}{c}\text { Stable ultimate } \\
\text { bearing capacity } \\
\text { KN/m }\end{array}$ & $\begin{array}{c}\text { Stable } \\
\text { safety } \\
\text { factor }\end{array}$ & $\begin{array}{c}\text { Normal stress at } \\
\text { mid-span upper } \\
\text { flange /Mpa }\end{array}$ & Instability mode \\
\hline 460 & 64 & Uniform load & 8.5 & 290.2 & 6.68 & 345 & Web flexion \\
460 & 80 & Uniform load & 7.4 & 256.2 & 5.9 & 345 & Web flexion \\
460 & 100 & Uniform load & 6.2 & 214.8 & 4.94 & 345 & Web flexion \\
460 & 120 & Uniform load & 4.8 & 166.6 & 3.83 & 345 & Web flexion \\
460 & 140 & Uniform load & 3.7 & 132.4 & 3.05 & 345 & Web flexion \\
460 & 160 & Uniform load & 2.9 & 106 & 2.44 & 345 & Web flexion \\
\hline
\end{tabular}

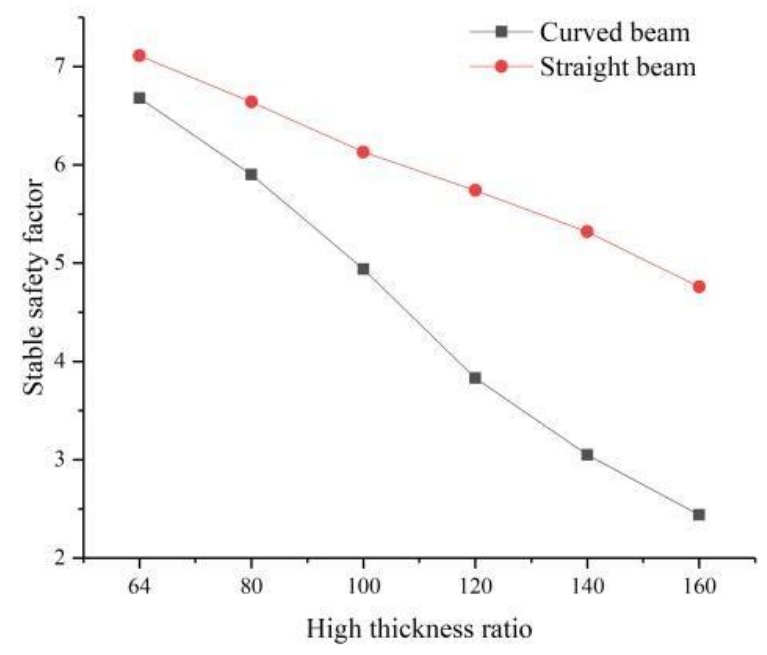

Fig. 8: Relationship between stability factor and high thickness ratio.

As can be seen from the Figure 8, as the height-to-thickness ratio of the web increases, the stability and safety factor of the structure gradually decreases, and the two are basically in a linear relationship;

The stability safety factor of curved beams is more affected by the web height-thickness ratio

\subsection{Curvature Radius}

By changing the curvature radius in the model, we got the following data. 
Table 9. Calculation results of curved beam.

\begin{tabular}{cccccccc}
\hline $\begin{array}{c}\text { radius } \\
/ \mathrm{m}\end{array}$ & $\begin{array}{c}\text { Center angle } \\
\mathrm{I}^{\circ}\end{array}$ & Load form & $\begin{array}{c}\text { Loading } \\
\text { factor } \lambda\end{array}$ & $\begin{array}{c}\text { Stable ultimate } \\
\text { bearing capacity } \\
\mathrm{KN} / \mathrm{m}\end{array}$ & $\begin{array}{c}\text { Stable } \\
\text { safety } \\
\text { factor }\end{array}$ & $\begin{array}{c}\text { Normal stress at } \\
\text { mid-span upper } \\
\text { flange /Mpa }\end{array}$ & $\begin{array}{c}\text { Instability } \\
\text { mode }\end{array}$ \\
\hline 1000 & 6 & Uniform load & 9 & 309 & 7.11 & 345 & Web flexion \\
800 & 7.5 & Uniform load & 8.9 & 305.4 & 7.03 & 345 & Web flexion \\
600 & 10 & Uniform load & 8.8 & 299.7 & 6.9 & 345 & Web flexion \\
500 & 12 & Uniform load & 8.7 & 296.3 & 6.82 & 345 & Web flexion \\
460 & 13.1 & Uniform load & 8.5 & 290.2 & 6.68 & 345 & Web flexion \\
200 & 30.1 & Uniform load & 6.7 & 231.9 & 5.34 & 345 & Web flexion \\
100 & 60.2 & Uniform load & 4.7 & 165.3 & 3.81 & 345 & Flap buckling \\
\hline
\end{tabular}

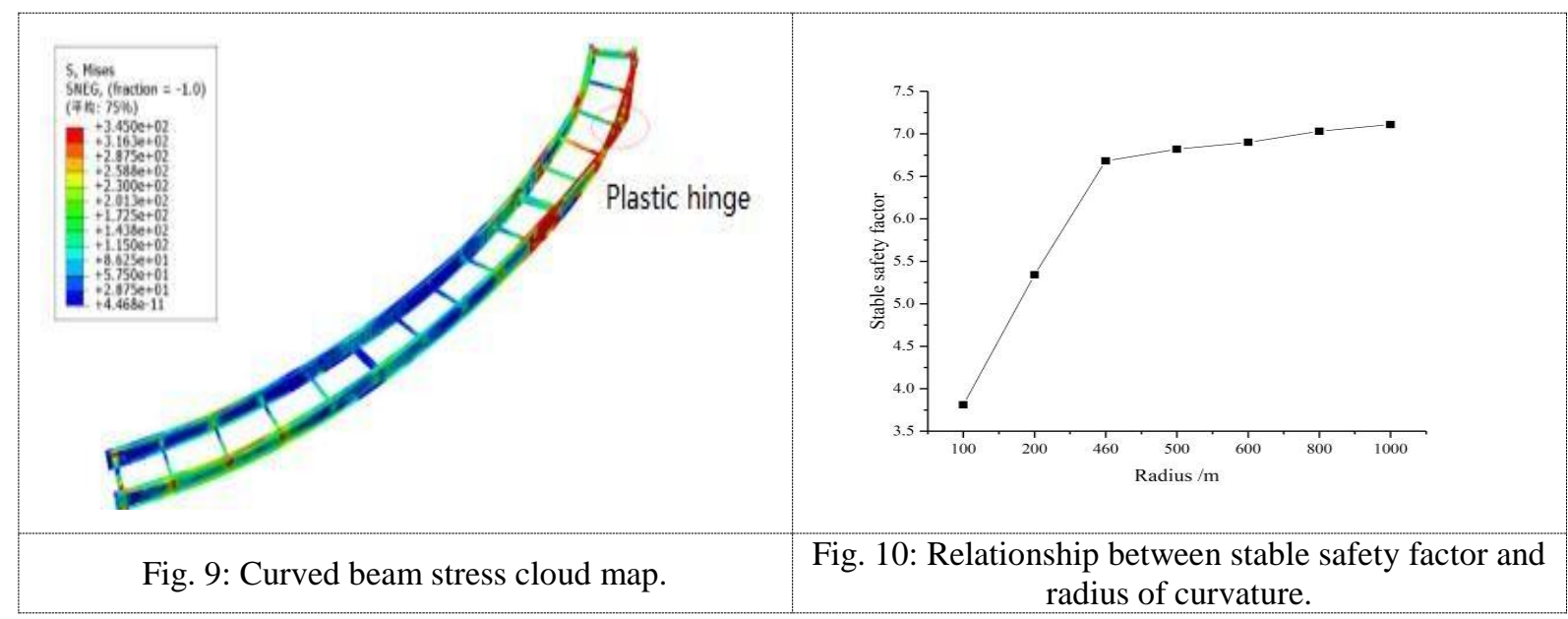

From the Figure 9 and 10, it can be seen that with the increase of the radius of curvature, the stability and safety factor of the structure gradually increases. The factor grows faster when radius $=100 \sim 500 \mathrm{~m}$, and the growth is more stable when radius $=600 \sim 1000 \mathrm{~m}$. All of outer main beam are unstable first.

\section{Conclusion}

Except for the width-to-thickness ratio of the compressed flange, the stability and safety of $3 \times 35 \mathrm{~m}$ straight beams are better than curved beams in the analysis of various parameters, and the stability and safety of curved beams are more affected by various structural parameters.

For $3 \times 35 \mathrm{~m}$ straight beams, from the perspective of stability, it is recommended to consider the $8.75 \mathrm{~m}$ beam spacing to save steel.

From the comprehensive consideration of structural stability, safety and steel consumption, it is recommended that the high-span ratio of medium-small-span steel-concrete composite beams be 1/20.

Local buckling will occur in the relatively thin positions of the compressed flange and the web. The value of the widthto-thickness ratio of the compressed flange of the straight beam is suggested.

\section{Acknowledgements}

Thanks to my future girlfriend for giving me the spiritual power, because she hasn't appeared yet. Otherwise I might not be able to finish this paper. Seriously, thank my family, colleagues and mentors for their careful support. 


\section{References}

[1] Nie J, Liu M, Ye L. (2005) Steel-concrete composite structure [M]. China Construction Industry Press.

[2] Ministry of Housing and Urban-Rural Development of the People's Republic of China. (2017) National Standards of the People's Republic of China. Code for Design of Steel Structures [M]. China Planning Press.

[3] Cao P. (1999) Study on the limit value of the height-to-thickness ratio of steel beam webs without stiffeners [J]. Steel Structures.

[4] Yuan M. (2005)Study on transverse normal stress and overall stability of steel-concrete composite beams [D]. Hehai University.

[5] Liu H, Zhu B, Cao P. (2006) Calculation and analysis of the overall stable bearing capacity of two- span continuous beams [J]. Steel Structure.

[6] Li X. (2007) Study on the stability of steel-concrete composite beams [D]. Central South University.

[7] Wang L. (2009) Overall stability analysis of welded I-section composite steel beam webs after buckling [D]. Xinjiang University.

[8] Chen S. (2013) Guidelines for Design of Steel Structure Stability (Third Edition) [M]. China Construction Industry Press.

[9] Ministry of Transport of the People's Republic of China. (2015) Industry Standards of the People's Republic of China.Code for Design of Highway Steel Structure Bridges [S]. People's Communications Press.

[10] Wu B. (2015) Mechanical characteristics and finite element analysis of continuous curved beam bridges [D]. Southwest Jiaotong University.

[11] Fan L. (2001) Bridge Engineering (Vol. 1) [M]. People's Communications Press.

[12] Sun G. (1995) Calculation of curved beam bridge [M]. People's Communications Press.

[13] Yao L. (1982) Practical calculation method for curved beam bridges [J]. Journal of Civil Engineering. 